\title{
Breastfeeding technique and the incidence of nipple traumas in puerperal women attended in a city hospital: intervention study
}

Thaize Carvalho Estrela do Vale Morais 1

iD https://orcid.org/0000-0002-2543-5153

Tâmara Oliveira de Souza 2

https://orcid.org/0000-0001-9150-4877

Graciete Oliveira Vieira 3

https://orcid.org/0000-0001-5354-718X

José de Bessa Júnior 4

https://orcid.org/0000-0003-4833-4889

Gilmar Mercês de Jesus 5

https://orcid.org/0000-0003-1702-217X

1-4 Mestrado Profissional em Saúde Coletiva. Universidade Estadual de Feira de Santana. Av. Transnordestina, s.n.Novo Horizonte. Feira de Santana, BA, Brasil.CEP: 44.036-900. E-mail: thaize_estrela@hotmail.com

5 Núcleo de Pesquisa e Extensão em Saúde (NUPES). Universidade Estadual de Feira de Santana. Feira de Santana, BA, Brasil.

\begin{abstract}
Objectives: to evaluate the effect of an intervention on the incidence of nipple trauma and the quality of breastfeeding technique in the first month of postpartum.

Methods: this is a quasi-randomized intervention study with 180 puerperal women equally distributed between experimental and control groups. The intervention was performed at a maternity and consisted of an educational session on breastfeeding technique. A descriptive analysis of the groups' characteristics was performed, comparing the frequencies of unfavorable parameters related to breastfeeding technique between groups. Pearson's chi-square test and Fisher's test were used, and $p \leq 0.05$ was adopted as the critical level of significance.

Results: at 30 days, $64 \%$ and $15 \%$ of the mothers used the technique correctly, respectively, in the experimental and control groups with $R R=4.87(C I 95 \%=2.93-8.34) ; N N T=1.96$ $(C 195 \%=1.61-2.72) ; p<0.001$. In the experimental group, a decrease was observed in the unfavorable parameters of the breastfeeding technique $(p \leq 0.05)$. The incidence of nipple trauma was $30 \%$ in the experimental group and $38.9 \%$ in the control group $(p=0.21)$.

Conclusions: the intervention was insufficient to prevent nipple trauma in the experimental group, but significantly improved the quality in the breastfeeding technique.
\end{abstract}

Key words Trauma, Breastfeeding, Incidence

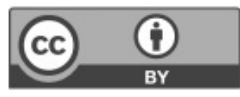




\section{Introduction}

Despite the recommendations for exclusive breastfeeding (EBF) in the first six months of a baby's life, ${ }^{1}$ many women discontinue breastfeeding due its difficult management. ${ }^{2-4}$

Nipple trauma is one of the factors associated with early breastfeeding interruption. ${ }^{2,5-7}$ This breast complication is a continuity solution of the nipple skin or areola caused by fissure, excoriation, erosion, laceration or vesicles, ${ }^{8}$ commonly associated with discomfort and pain during breastfeeding. 3,9

The incidence of nipple trauma during breastfeeding ranges from 11 to $96 \% .10-12$ Also, 80 to $95 \%$ of nursing mothers experience some degree of nipple pain in the first week after childbirth, and $26 \%$ report severe pain. These determinants contribute to the interruption of EBF and early weaning. 5 Nipple trauma is often the gateway to pathogenic microorganisms, and having mastitis 12,13 is a significant complication. Lactational mastitis is an inflammatory process of the breast, which may or may not be associated with infections, and Staphylococcus aureus is the most common infectious agent. 14

Among the factors associated with nipple lesion, the inadequate breastfeeding technique concerning is the positioning and the grip. $12,15-17$ A proper breastfeeding technique does not injure nipple and areola, and favors effective breast suction 17 and emptying. The proper breastfeeding technique has been cited as an essential factor in preventing nipple trauma and contributing as well to breastfeeding successfully. $3,10,12,15,18$ In contrast, inadequate positioning and grip interfere with breast milk suction and extraction dynamics, hinder emptying the breast and cause nipple injuries. 11

Nipple traumas commonly appear in the first week after childbirth, at the onset of the breastfeeding process. 19 Some intervention studies targeting breastfeeding technique showed that the frequency of complications related to breastfeeding was lower in the breastfeeding women's group that received the intervention. 19,20 However, others did not observe a positive impact of the intervention on the quality of the breastfeeding technique. 11,21

Although different interventions have been designed to improve the breastfeeding technique and reduce pain and nipple trauma, it is not very clear which method is the most effective. 16 Therefore, it is crucial to test the hypothesis that an intervention directed for breastfeeding implies a positive effect with an improved quality technique and lowered the incidence of nipple trauma.

This study aimed to evaluate the effect of an intervention on the breastfeeding grip and positioning on the incidence of nipple trauma and the quality on the breastfeeding technique in the first month of postpartum in puerperal women attended at a hospital in the city of Feira de Santana (BA), Brazil.

\section{Methods}

This is a quasi-randomized intervention study with a variable exposure to a directed intervention on the breastfeeding technique and outcomes, the incidence of nipple trauma, and the quality on the breastfeeding technique in the first month after childbirth, conducted in 2015 at Hospital Inácia Pinto dos Santos (HIPS), a Child-Friendly Hospital.

The calculated sample was based on the nipple trauma incidence of $43.3 \%$, as shown in a previous study, 22 and would consider the minimum detectable difference between the groups of $20 \%$ for the result of the intervention to be significant. The sample was calculated using a $95 \%$ confidence level and $80 \%$ of strength, considering $Z \alpha$ equal to 1.96 and $Z \beta$ equal to 0.84 . Thus, a minimum sample of 90 mothernewborn binomials was estimated for the control group, and 90 for the experimental group.

Puerperal women who gave birth within 48 hours before the data collection and who met the inclusion criteria (mothers residing in Feira de Santana (BA), mother-newborn binomials in joint accommodation and maternal breastfeeding) were invited to participate in the study until the minimum number of participants defined in the calculated sample was reached. Twin babies or hospitalized babies in the neonatal unit and puerperal women with nipple trauma or mastitis were not included in the study in the first approach.

The study sample consisted of mother-newborn binomials attended at HIPS. The dyads were included in this study in the period of February to July 2015, although the approach with the mothers in the experimental and control groups took place in alternated weeks, to avoid having mothers from different groups in the same ward. The researchers made a simple drawing to define which group the participants would be allocated to starting the data collection by the experimental group (Figure 1).

Data were collected in two occasions: at the maternity and 30 days after childbirth by a properly trained team, consisting of two nurses and a nutritionist. They were responsible for selecting the sample, interviewing the mothers, observing the breastfeeding, and evaluating the breasts.

At the maternity, the mothers of the control and 
experimental groups were interviewed to obtain sociodemographic data, related to prenatal care, childbirth and breastfeeding, and data related to the newborn. Then, breast examination was performed to assess their characteristics, confirm the absence of nipple trauma, and investigate the presence of breast engorgement and mastitis.

A pilot study was carried out with nine mothers, corresponding to $5 \%$ of the sample, to test the logistic of the study and the data collection instruments.

Breastfeeding was also observed at the maternity by using a form recommended by the World Health Organization. ${ }^{23}$ This procedure was performed only in the experimental group, as per ethical standards that do not allow the researcher's omission in possible cases identify as poor breastfeeding techniques. Afterwards, the intervention was carried out in three stages: Stage 1 - exhibition of the video "Amamentação muito mais do que alimentar a criança" (Breastfeeding is much more than feeding the child) reproduced by the Ministry of Health and the Brazilian Pediatrics Society, 24 which addresses the breastfeeding technique and the benefits of maternal breastfeeding. The video was shown in the presence of one of the researchers, individually or in a group of maximum three women. At the end of the exhibition, a video selection was presented individually with specific images on the breastfeeding technique; Stage 2 - verbal guidance on the breastfeeding technique and the benefits of maternal breastfeeding; Stage 3 - demonstration of the correct breastfeeding technique using a breast model and doll.

At the end of the demonstration, the mother reproduced the procedures taught with the infant. Proper guidance was given if an unfavorable parameter of the breastfeeding technique was identified. Any concerns were clarified, and the child's return was scheduled for an appointment with a pediatrician at the Institution thirty days after birth.

It is worth mentioning that the intervention carried out in this study, differed from which already occurs routinely in the service where the study was developed concerning the resources that were used in the same approach (breast model, doll and video), the type of approach (individual and group) and individual demonstration of the breastfeeding technique. The mothers of the control group did not receive the intervention proposed by the study, but were guided

\section{Figure 1}

Flow chart on the progress through the phases of an intervention study.

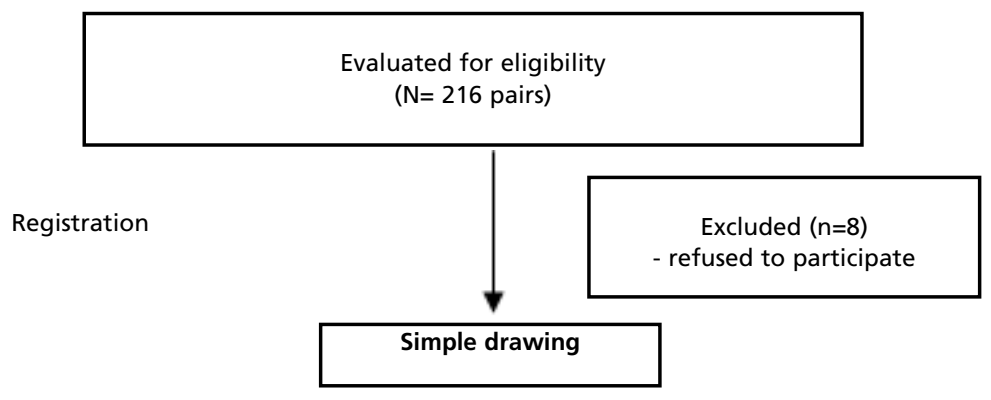

Intervention Group

Control Group

Follow-up

Follow-up loss $(n=13)$

- mother did not return for outpatient consultation or was not interviewed at 30 days

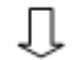

90 pairs analyzed
Follow-up loss $(n=15)$

- mother did not return for outpatient consultation or was not interviewed at 30 days

Analysis

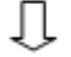

90 pairs analyzed 
by the research team regarding the benefits of breastfeeding and also received guidance from the health professional team at HIPS, since the following procedures are already carried out in its routine and as it is a hospital accredited by the Child-Friendly Hospital Initiative: Monday through Friday, guidance in the wards on the benefits of breastfeeding and its management, with the delivery of an information folder, the group educational activities were performed on specific dates.

Thirty days after birth, infants in the control and experimental groups returned for a consultation with the pediatrician at the institution, following the service routine. Then, the mothers of both groups were interviewed about the child's eating pattern. After the interview, breast examinations and breastfeeding observation were performed in both groups using the same data collection instruments employed at the maternity. Home visits were necessary due to the absence of some mothers at the consultations. Fifty-two $(28.9 \%)$ of the 180 puerperal women/infant pairing were visited at home.

The aspects related to the breastfeeding technique were obtained through the observation of breastfeeding, using the instrument recommended by the World Health Organization.23 Parameters indicative of proper positioning of the newborn were used to evaluate the breastfeeding technique (baby close to the mother's body; head and trunk aligned; baby's body well supported), adequate grip (mouth wide open; lower lip turned out; baby's chin touching the breast; asymmetrical grip, with more areola visible above the baby's mouth) and adequate suction (slow and deep suction in periods of activity with breaks, swallowing is noted or heard). The breastfeeding technique was considered correct when all the parameters mentioned above were favorable.

Nipple trauma was defined as the occurrence of fissure, excoriation, erosion, laceration, vesicles, ecchymosis, and erythema in the nipple-areolar region, 8 ascertained in the breast examination performed at the consultation with the pediatrician scheduled for thirty days after childbirth. Moreover, the puerperal women's self-reports regarding the occurrence of these lesions in the first month of postpartum were considered. As the mothers who had nipple injuries in the first 48 hours after childbirth were excluded from the study, only women who had new injuries after hospital discharge were included in the calculation of the nipple trauma incidence. Maternal sociodemographic variables, characteristics related to pregnancy, newborn, and breastfeeding were also researched.

The Statistical Package for Social Sciences
(SPSS) version 10.0 was used to build the database and perform statistical analysis. The absolute and relative frequencies of all variables collected were calculated. The characteristics of the control and experimental groups were compared, as well as the frequencies of the unfavorable parameters related to positioning, grip, and suction were observed 30 days after childbirth. The breastfeeding technique was compared between the pairs of the two groups 30 days after childbirth, and the number needed to treat (NNT) was calculated, which represents the estimate of the number of individuals who should receive the intervention to produce the positive outcome. The NNT is equivalent to the reciprocal of absolute risk reduction or risk difference. 25 Pearson's chi-square test and Fisher's exact test were used, and $p \leq 0.05$ was adopted as a critical level of significance, with a confidence interval of $95 \%$.

The Research Ethics Committee of the Universidade Estadual de Feira de Santana approved the study CAAE: 39280614.9 .0000 .0053 . The data were collected after signing the informed consent form.

\section{Results}

Of the 216 mother/newborn binomials eligible for the study, $8(3.7 \%)$ did not participate due to maternal refusal, and $28(13 \%)$ were lost during the follow-up, which resulted in 180 binomials distributed as follows: 90 in the control group and 90 in the intervention group. The characteristics of the puerperal women and their respective newborns were similar between the groups (Table 1).

In the breast examination, $72.2 \%$ and $81.1 \%$ of the nursing mothers had normal nipples, $26.7 \%$ and $16.7 \%$ had flat nipples, and $1.1 \%$ and $2.2 \%$ malformed nipples in the experimental and control groups, respectively. There was no significant difference between the groups regarding the presence of flat $(p=0.11)$ and malformed nipples $(p=0.63)$. The occurrence of breast engorgement in the first month after childbirth also did not differ between the experimental group (3.3\%) and the control group (2.2\%) $(p=0.66)$.

A higher incidence of the correct breastfeeding technique was identified in the experimental group $(64 \%, 57 / 89)$ compared to the control group $(15 \%$, $13 / 86) \mathrm{RR}=4.87(\mathrm{CI} 95 \%=2.93-8.34) ; \mathrm{NNT}=1.96$ $(\mathrm{CI} 95 \%=1.61-2.72) ; p<0.001$. The Absolute Risk Reduction (ARR) calculation showed that for every 100 mothers exposed to the training, 64 adopted the correct breastfeeding technique, and in 49 of them, this outcome was due to the intervention ( $\mathrm{ARR}=49$ ). 
When comparing the frequencies of the unfavorable parameters to the breastfeeding technique at 30 days after childbirth between the experimental and control groups, a better quality of the technique was observed in the experimental group, with a significant difference in the following parameters: baby's body distant from the mother's body; chin does not touch the breast; the baby is not well supported; mouth slightly open; non-asymmetric grip; lower lip turned inwards, and the presence of only rapid suctions with clicks (Table 2).

Regarding to nipple trauma, $30 \%$ and $38.9 \%$ of the women self-reported nipple injury, respectively, in the experimental and control groups, with no significant difference between groups $(p=0.21)$. Concerning the type of nipple trauma, the most frequent injury was a fissure, found in $20 \%$ of the puerperal women in the experimental group and $27.8 \%$ in the control group. The other injuries presented by the puerperal women are shown in Table 3

\section{Discussion}

The intervention conducted in the current study on the breastfeeding technique produced a beneficial effect, as it significantly reduced the frequency of unfavorable parameters to the quality of the technique in the experimental group. However, it did not affect the incidence of nipple trauma.

The magnitude between the exposure and the technical outcome of breastfeeding was 4.2 , that is, the puerperal women who did not receive the intervention were 4.2 times more likely to adopt the incorrect technique when compared to the experimental group. The value of NNT=1.96 $(p<0.001)$ showed that a case of incorrect breastfeeding technique could be prevented in approximately one in every two puerperal women who received the intervention measures. This parameter that helps health professionals weigh the risks and benefits of a given therapeutic measure, indicated that the establishment of intervention measures in the breastfeeding technique has a positive impact on its quality.

The breastfeeding technique in the experimental group improved in almost all the parameters of positioning and grip. Other intervention studies have also identified improved breastfeeding technique. In a study carried out in Australia, the women in the experimental group had better scores concerning the newborn's position and grip during breastfeeding. 23 Another successful intervention was carried out in the United Kingdom, where 395 mother/newborn pairings were evaluated on the breastfeeding tech- nique during hospitalization after childbirth. The authors found that $56 \%$ of the nursing mothers had an adequate technique26after the intervention. A higher value $(64 \%$ in the experimental group versus $15 \%$ in the control group) was found in the current study.

In contrast, another intervention study found no significant difference when comparing the means of the number of unfavorable parameters to breastfeeding between the experimental and control groups, both in the maternity and at 30 days after childbirth. ${ }^{21}$ The difference between the referred intervention and of this current study was the use of a video as an audiovisual resource to show the breastfeeding technique.

The intervention of the current study also differed from what is usually performed at the hospital, where the study was conducted concerning the use of audiovisual resources and instruments such as breast model and doll for individual demonstration of the correct breastfeeding technique. These measures seem to have achieved a positive outcome. As they are easy to access and apply, they can be incorporated into hospital routines, especially concerning orientations carried out individually, face-to-face, as they are more effective 27 than those performed in groups.

In this study, noteworthy was the proportion of $47.8 \%$ of the "non-asymmetric grip" parameter in the control group at 30 days in relation to the experimental group, in which the proportion was $14.6 \%$. This parameter suffered the most significant impact with the intervention. Similarly, this item showed a significant improvement $(p<0.001)$ in another intervention study, at thirty days of the baby's life. 21

The adequate breastfeeding technique has been described as an essential preventive measure against nipple trauma.3,19,20,26 However, in this study, the intervention explicitly directed for the breastfeeding technique did not significantly reduce nipple trauma. The same occurred in three other intervention studies. ${ }^{20,21,28}$

A study carried out in Australia, 20 where puerperal women received individual guidance on positioning and grip 24 hours after childbirth, found no significant difference in the incidence of nipple trauma between the experimental group (17\%) and the control group (20\%). In the study conducted in England, 28 the intervention consisted of an interference performed by a qualified midwife, who addressed positioning and grip during breastfeeding. No significant differences were found in the incidence of breastfeeding problems, as $30.3 \%$ and $37.8 \%$ had sore or fissured nipples in the experi- 
Table 1

\begin{tabular}{|c|c|c|c|c|c|}
\hline \multirow{2}{*}{$\begin{array}{l}\text { Characteristics of the } \\
180 \text { mother-NB pairs* }\end{array}$} & \multicolumn{2}{|c|}{ Experimental Group } & \multicolumn{2}{|c|}{ Control Group } & \multirow[t]{2}{*}{$p$} \\
\hline & $\mathrm{n}$ & $\%$ & $\mathrm{n}$ & $\%$ & \\
\hline Mothers aged $\geq 20$ years & 62 & 68.9 & 66 & 73.3 & 0.51 \\
\hline Overweight and/or obesity *** & 46 & 68.7 & 38 & 52.0 & 0.20 \\
\hline Mother with > 9 years of schooling & 50 & 55.6 & 49 & 54.4 & 0.88 \\
\hline Mother with mixed skin color & 51 & 56.7 & 55 & 61.1 & 0.48 \\
\hline Cohabiting of the couple & 79 & 87.8 & 74 & 82.2 & 0.29 \\
\hline Income $>1$ minimum wage & 31 & 41.9 & 39 & 48.8 & 0.39 \\
\hline Tobacco use & 3 & 3.3 & 2 & 2.2 & 0.65 \\
\hline Nipple traumas in previous pregnancy & 23 & 48.9 & 34 & 65.4 & 0.09 \\
\hline Vaginal childbirth & 60 & 66.7 & 50 & 55.6 & 0.12 \\
\hline Primiparity & 43 & 47.8 & 38 & 42.2 & 0.45 \\
\hline Prenatal care with $\geq 6$ consultations & 59 & 67.0 & 52 & 57.8 & 0.23 \\
\hline \multicolumn{6}{|l|}{ Guidance on breastfeeding } \\
\hline technique in prenatal care & 28 & 31.8 & 39 & 43.3 & 0.12 \\
\hline \multicolumn{6}{|l|}{ Guidance on the importance of } \\
\hline breastfeeding in prenatal care & 41 & 47.8 & 50 & 56.2 & 0.11 \\
\hline Participation in prenatal care course & 8 & 8.9 & 9 & 10.0 & 0.39 \\
\hline Participation in breastfeeding course & 5 & 5.7 & 12 & 13.3 & 0.12 \\
\hline First child breastfed up to 1 year $* * * *$ & 17 & 37.8 & 25 & 48.1 & 0.30 \\
\hline \multicolumn{6}{|l|}{$\begin{array}{l}\text { Mean breastfeeding time of } \\
\text { previous children } * * * * *\end{array}$} \\
\hline$\geq 6$ months & 38 & 84.4 & 42 & 80.8 & 0.63 \\
\hline Sunbathing nipple before childbirth & 31 & 34.4 & 18 & 20.0 & 0.14 \\
\hline \multicolumn{6}{|l|}{ Use of cream on nipples } \\
\hline before childbirth & 18 & 20.0 & 10 & 11.1 & 0.14 \\
\hline \multicolumn{6}{|l|}{ Characteristic of nipples } \\
\hline Normal nipples & 65 & 72.2 & 73 & 81.1 & 0.57 \\
\hline Breast engorgement at the maternity & 3 & 3.3 & 2 & 2.2 & 0.66 \\
\hline \multicolumn{6}{|l|}{ Characteristics of NBs } \\
\hline Female NB & 49 & 54.4 & 50 & 55.6 & 0.88 \\
\hline NB's birth weight $<2500 \mathrm{~g}$ & 3 & 3.3 & 8 & 8.9 & 0.11 \\
\hline Use of pacifier at the maternity & 4 & 4.4 & 5 & 5.6 & 0.73 \\
\hline \multicolumn{6}{|l|}{ NB received supplement } \\
\hline at the maternity & 3 & 3.4 & 2 & 2.2 & 0.64 \\
\hline \multicolumn{6}{|l|}{ NB breastfed in the first hour } \\
\hline after childbirth & 30 & 33.3 & 21 & 23.3 & 0.14 \\
\hline
\end{tabular}

*NB = newborn; ** Pearson's Chi-square test and Fisher's test; ** Considering mothers who reported weight and height: 67 from the experimental group and 73 from the control group; $* * * *$ Considering mothers who already had children: 87 from the experimental group and 82 from the control group; $* * * *$ Considering mothers whose first child was one year or older: 45 from the experimental group and 52 from the control group. 
Frequency of unfavorable parameters related to positioning, grip and suction in the experimental and control groups 30 days after childbirth. Feira de Santana (BA), Brazil, 2015.

\begin{tabular}{|c|c|c|c|c|c|c|c|}
\hline \multirow[t]{2}{*}{ Variables } & \multicolumn{2}{|c|}{ Experimental Group } & \multicolumn{2}{|c|}{ Control Group } & \multirow[t]{2}{*}{$\mathbf{R R}$} & \multirow[t]{2}{*}{$\mathrm{Cl} 95 \%$} & \multirow[t]{2}{*}{$p$} \\
\hline & $\mathrm{n}$ & $\%$ & $\mathrm{n}$ & $\%$ & & & \\
\hline \multicolumn{8}{|c|}{ Breastfeeding technique parameters } \\
\hline \multicolumn{8}{|l|}{ Mother/baby positioning } \\
\hline Baby distant from mother & 7 & 7.9 & 27 & 30.7 & 3.9 & $1.79-8.49$ & $<0.001$ \\
\hline Unaligned head and torso & 6 & 6.7 & 13 & 14.9 & 2.22 & $0.88-5.57$ & 0.15 \\
\hline \multicolumn{8}{|l|}{ Baby is not well supported (only } \\
\hline shoulder or head supported) & 2 & 2.2 & 21 & 23.9 & 10.6 & $2.57-43.94$ & $<0.001$ \\
\hline \multicolumn{8}{|l|}{ Baby's grip } \\
\hline Mouth slightly open & 7 & 7.8 & 20 & 22.7 & 2.89 & $1.29-6.49$ & $<0.001$ \\
\hline Chin not touching the breast & 3 & 3.4 & 28 & 31.8 & 9.44 & $2.98-29.92$ & $<0.001$ \\
\hline \multicolumn{8}{|l|}{ Non-asymmetric grip (the areola } \\
\hline \multicolumn{8}{|l|}{ was no longer visible above } \\
\hline the baby's mouth) & 13 & 14.6 & 43 & 49.4 & 2.88 & $1.65-5.03$ & $<0.001$ \\
\hline Lower lip turned inward & 13 & 14.6 & 37 & 42.0 & 2.9 & $1.65-5.03$ & $<0.001$ \\
\hline \multicolumn{8}{|l|}{ Suction } \\
\hline Only quick sucking with clicks & - & - & 9 & 10.3 & - & - & $<0.001$ \\
\hline \multicolumn{8}{|l|}{ Click of the lips is heard, but } \\
\hline not the swallowing & 2 & 2.2 & 7 & 8.0 & 3.88 & $0.76-16.76$ & 0.15 \\
\hline
\end{tabular}

* Pearson's Chi-square test and Fisher's test.

Table 3

Frequency of nipple trauma observed in the experimental and control groups 30 days after childbirth. Feira de Santana (BA), Brazil, 2015

\begin{tabular}{|c|c|c|c|c|c|c|}
\hline \multirow[t]{2}{*}{ Variables } & \multicolumn{2}{|c|}{ Experimental Group } & \multicolumn{2}{|c|}{ Control Group } & \multirow[t]{2}{*}{$\mathbf{R R}$} & \multirow[t]{2}{*}{$\mathrm{Cl} 95 \%$} \\
\hline & $\mathrm{n}$ & $\%$ & $\mathrm{n}$ & $\%$ & & \\
\hline \multicolumn{7}{|l|}{ Nipple trauma } \\
\hline Fissure & 18 & 20.0 & 25 & 27.8 & 1.39 & $0.82-2.36$ \\
\hline Excoriation & 5 & 5.6 & 2 & 2.2 & 0.4 & $0.08-2.0$ \\
\hline Erythema & 3 & 3.3 & 4 & 4.4 & 1.33 & $0.31-5.8$ \\
\hline Bruise & - & - & 1 & 1.1 & - & - \\
\hline Laceration & - & - & 1 & 1.1 & - & - \\
\hline Fissure and erythema & 1 & 1.1 & 1 & 1.1 & - & - \\
\hline Excoriation and erythema & - & - & 1 & 1.1 & - & - \\
\hline
\end{tabular}


mental and control group, respectively. The third study was carried out in Brazil,21 and in this one, the puerperal women were instructed at the maternity about the breastfeeding technique, emphasizing aspects related to positioning and the correct grip during breastfeeding and manual milking teaching. It was noted that the incidence of nipple trauma in the group of mothers who received the intervention $(43.2 \%)$ was similar to the control group $(48.9 \%)$ when were assessed at seven days. At 30 days, there was no difference in the incidence of trauma in the two groups, at $8.5 \%$ and $9.1 \%$, respectively, in the experimental and control groups.

This present study is similar to the three mentioned previously, concerning the fact that the intervention was carried out at a single moment. On the other hand, other interventions have been successful. In a study carried out in Australia, in which the intervention consisted of an orientation session on breastfeeding technique, the women who received the intervention had better scores when assessing the newborn's positioning and grip during breastfeeding, and a lower incidence of nipple trauma, 53\% in the experimental group versus $100 \%$ in the control group. ${ }^{19}$ It is worth mentioning that this intervention was performed with nulliparous pregnant women, at the end of pregnancy (36 weeks), a characteristic that may have contributed to the success of the intervention, since the singularities of the first days after childbirth may compromise the assimilation of the guidelines provided in this period.

In the current study, other factors rather than the breastfeeding technique and those researched may have affected the experimental and control group differently and contributed to the results found, such as oral dysfunctions in the child, excessively short tongue brake, non-nutritive prolonged sucking, improper use of breast pumps or use of nipple protectors, and among others. ${ }^{29,30}$

It is also relevant to highlight some methodological limitations of this study in order to understand the results found, such as information bias, as the breast examination was only performed at the maternity and 30 days after the intervention, and it is necessary to consider the maternal limitation in identifying nipple trauma. The nursing mothers may have failed to report any nipple injury that occurred during this period because they did not have a good view of the nipple itself or because they were unable to do so, although this evaluation method can assist in monitoring this condition. Another limitation of the study was that evaluators were aware of which group the puerperal women belonged to.

The intervention on the positioning and grip carried out in the maternity had a positive impact on the quality of the breastfeeding technique, strengthening the established knowledge that the institution with intervention measures can facilitate breastfeeding. Thus, care for the puerperal women before hospital discharge is essential, with the observation of the breastfeeding and demonstration of the correct breastfeeding technique. Therefore, a trained team, with sufficient knowledge to intervene early at the first signs of poor positioning and grip, is required and is an important measure to ensure successful breastfeeding.

Contradictorily, the intervention did not prevent the occurrence of nipple lesions, which suggests that an intervention performed at a single moment is not enough to prevent nipple trauma. Furthermore, other factors rather than the breastfeeding technique may have contributed to the results found.

\section{Authors' contribution}

Morais TCEV and Souza TO participated in the concept and design of the study, data acquisition, and analysis. Jesus GM and Bessa Júnior J participated in the data analysis. Vieira GO participated in the concept and design of the study and data analysis. All authors participated in data interpretation, writing, and critical review of the manuscript. 


\section{References}

1. Kramer M, Kakuma R. Optimal duration of exclusivebreastfeeding.Cochrane Database Syst Rev. 2012; 8: CD003517.

2. Ahluwalia I, Morrow B, Hsia J. Why do women stop breastfeeding? Findings from the Pregnancy Risk Assessment and Monitoring System.Pediatrics. 2005;116 (6): 1408-12.

3. Kent JC, Ashton E, Hardwick CM, Rowan MK, Chia ES,Fairclough KA, Menon LL, Scott C, Mather-Mccaw G, Navarro K, Geddes DT. Nipple Pain in Breastfeeding Mothers: Incidence, Causes and Treatments. Int J Environ Res Public Health. 2015; 12 (10): 12247-63.

4. World Health Organization (WHO). Infant and young child feeding: model chapter for textbooks for medical students and allied health professionals.Geneva; 2009.

5. Coca KP, Gamba MA, Silva RS, Abrao ACFV. A posição de amamentar determina o aparecimento do trauma mamilar? Rev Esc Enferm USP. 2009; 43 (2): 446-52.

6. Vieira GO, Martins C, Vieira TO, Oliveira NF, Silva LR. Fatores preditivos da interrupção do aleitamento materno exclusivo no primeiro mês de lactação. J Pediatr (Rio J.). 2010;86 (5): 441-4.

7. Oliveira CNT, Oliveira MV. Prevalência de aleitamento materno exclusivo e fatores associados ao desmame precoce no município de Vitória da Conquista-BA. C\&DRev Eletr Fainor, Vitória da Conquista. 2012; 5(1): 160-74.

8. VinhaVHP.TraumasMamilares(ferimentos):prevençãoecuidados.ln:VinhaVHP.Olivrodaamamentação.SãoPaulo:C LR Balieiro; 1999.p.45-54

9. Thompson R, Kruske S, Barclay L, Linden K, Gao Y, Kildea S. Potential predictors of nipple trauma from an in home breastfeeding programme: a cross-sectional study. Women Birth. 2016; 29 (4): 336-44

10. Centuori S, Burmaz T, Ronfani L, Fragiacomo M, Quintero S, Pavan C, Davanzo R, Cattaneo A. Nipplecare, sore nipplesandbreastfeeding: a randomizedtrial. J Hum Lact. 1999; 15 (2): 125-30.

11. Weigert EML, Giugliani ERJ, França MCT, Oliveira LD, Bonilha A, Espírito Santo LC et al. Influência da téc $\neg$ nica de amamentação nas frequências de aleitamento materno exclusivo e lesões mamilares no primeiro mês de lactação. J Pediatr. 2005; 81 (4): 310-6.

12. Santos KJS, Santana GS, Vieira TO, Santos CAST, Giugliani ERJ, Vieira GO. Prevalence and factors associated with cracked nipples in the first month postpartum. BMC Pregnancy Childbirth. 2016; 16: 209.

13. Cullinane M, Amir LH, Donath SM, Garland SM, Tabrizi SN, Payne MS, Bennett CM. Determinants of mastitis in women in the CASTLE study: a cohort study. BMC Fam Pract. 2015; 16 (1): 181.

14. Dias JS, Vieira TO, Vieira GO. Fatores associados ao trauma mamilar no período lactacional: uma revisão sistemática. Rev Bras Saúde Mater Infant. 2017; 17 (1): 2742 .

Received on September 3, 2019

Final version presented on February 9, 2020

Approved on March 27, 2020
15. Goyal C, Banginwar AS, Ziyo F, Toweir AA. Breastfeeding practices: Positioning, attachment(latch-on) and effective suckling - A hospital-basedstudy in Libya. J Family Community Med. 2011; 18 (2): 74-9.

16. Vieira F, BachionMM, Mota DD, Munari DB. Asystematic reviewof theinterventionsfornippletraumainbreastfeedingmothers.J Nurs Scholarsh. 2013; 45 (2): 116-25.

17. Dennis CL, Jackson K, Watson J. Interventions for treating painful nipples among breastfeeding women. Cochrane DatabaseSystRev. 2014; 12: 1-72.

18. Shimoda G,Aragaki I, Sousa C, Silva I. Associação entre persistência de lesão de mamilos e condições de aleitamento materno. Rev Min Enferm. 2014; 18 (1): 68-74.

19. Duffy EP, Percival P, Kershaw E. Positive effects of an antenatal group teaching session on postnatal nipple pain, nipple trauma and breastfeeding rates. Midwifery. 1997;13 (4): 189-96.

20. Henderson A, Stamp G,Pincombe J.Postpartum positioning and attachment education for increasing breastfeeding: a randomized trial. Birth. 2001; 28 (4): 236-42.

21. Oliveira LD, Giugliani ER, Eepírito Santo LC do, Cavalheiro M, França T, Weigert EML. Effect of Intervention to Improve Breastfeeding Technique on the Frequency of Exclusive Breastfeeding and LactationRelated Problems.J Hum Lact. 2006;22 (3): 315-21.

22. Santos KJS. Fatores associados à mastite lactacional e trauma mamilar [dissertação].Feira de Santana: Programa de Pós-Graduação em Saúde Coletiva da Universidade Estadual de Feira de Santana; 2013.

23. WHO(World Health Organization). Positioning a baby at the breast.In: WHO. Integrated Infant Feeding Counselling: a Training Course. Trainer's Guide;2004.

24. Brasil. Ministério da Saúde. Secretaria de Atenção à Saúde; Sociedade Brasileira de Pediatria. Amamentação:muito mais do que alimentar a criança. [S.1.: s.n., 2010]. 1 DVD (22 $\mathrm{min})$, color. Em português e espanhol.

25. Oliveira Filho PF de. Epidemiologia e bioestatística: fundamentos para a leitura crítica. 1 Ed. Rio de Janeiro: Rubio; 2015.

26. Ingran J, Johnson D, Greenwood R. Breastfeeding in Bristol: teaching good positioning and support fathers and families.Midwifery.2002; 18: 87-101.

27. McFadden A, Gavine A, Renfrew MJ, Wade A, Buchanan P, Taylor JL, Veitch E, Rennie AM, CrowtherSA, Neiman S, MacGillivray S. Support for healthy breastfeeding mothers with healthy term babies. Cochrane Database Syst Rev. 2017; 2: CD001141.

28. Wallace LM, Dunn OM, Alder EM, Inch S, Hills RK, Law SM. A randomised-controlled trial in England of a postnatal midwifery intervention on breastfeeding duration.Midwifery.2006; 22: 262-73.

29. Biancuzzo M. Maternal physical assessment and counseling. In: Biancuzzo M. Breastfeeding the newborn. St. Louis: Mosby. 1999; p. 226-304.

30. Brasil. Ministério da Saúde. Saúde criança:nutrição infantil/ Aleitamento materno e alimentação complementar. Brasília, DF; 2009. 